\title{
Arachnoid granulations of the middle cranial fossa
}

\author{
R. Shane Tubbs $\cdot$ Marios Loukas
}

Received: 28 October 2010 / Accepted: 26 November 2010 / Published online: 8 December 2010

(C) Springer-Verlag 2010

Dear Prof. Duparc,

We would like to applaud Chen et al. [2] on a superb study evaluating other locations of arachnoid granulations within the middle cranial fossa. These data help explain and further elucidate possible cerebrospinal fluid absorption that occurs outside of the large arachnoid granulations found within the superior sagittal sinus and lacunae lateralis (Weed [4] first described CSF reabsorption via the arachnoid granulations along the superior sagittal sinus in 1923). This is exemplified in patients who have partial occlusion of the superior sagittal sinus but do not develop hydrocephalus. It is noteworthy that standard sources and textbooks usually do not mention such non-superior sagittal sinus/lateral lacunae locations. Other less known sites have been found along cranial nerves as they exit the cranium (e.g. jugular foramen), in the internal auditory meatus near the greater petrosal nerve's emergence from the geniculate ganglion, and from the sheath of the trigeminal nerve as its parts traverse the cavernous sinus [1]. Additionally, these structures or at least arachnoid villi are identified along the spinal axis particularly at the nerve root sleeves [3]. We look forward to additional studies by these authors.

\section{References}

1. Bergmann L (1942) Studies of the blood vessels of the human Gasserian ganglion. Anat Rec 82:609-629

2. Chen F, Deng XF, Liu B, Zou LN, Wang DB, Han H (2010) Arachnoid granulations of middle cranial fossa: a population study between cadaveric dissection and in vivo computed tomography examination. Surg Radiol Anat (in press)

3. Tubbs RS, Hansasuta A, Stetler W, Kelly DR, Blevins D, Humphrey R, Chua GD et al (2007) Human spinal arachnoid villi revisited: immunohistological study and review of the literature. J Neurosurg Spine 7:328-331

4. Weed LH (1923) The absorption of cerebrospinal fluid into the venous system. Am J Anat 31:191-221

R. S. Tubbs $(\square)$

Birmingham, AL, USA

e-mail: Shane.Tubbs@chsys.org

M. Loukas

St. George's University, Grenada, West Indies 